\title{
Microvascular reconstruction for maxillofacial defects: a retrospective analysis of outcomes and complications in 121 consecutive cases
}

\author{
SeongRyoung Kim, Dong-Hun Lee and Kang-Min Ahn * (D)
}

\begin{abstract}
Background: Microvascular reconstruction is the treatment of choice after oral cancer ablation surgery. There are few published studies of free flap survival among Korean populations. This study aimed to determine the survival rate after 121 consecutive cases of maxillofacial microvascular reconstruction and to analyze the complications associated with microsurgery.

Methods: This study included consecutive patients who underwent microsurgical reconstruction with free flaps, from January 2006 through September 2019, performed by a single surgeon at the oral and maxillofacial surgery department of a tertiary medical center. A total of 121 cases were reviewed retrospectively. The flap survival rate, flap type, radiotherapy history, complications, and treatment results were analyzed.

Results: Four different flap types were used for microvascular reconstruction: radial forearm $(n=65)$, fibula $(n=34)$, latissimus dorsi $(n=21)$, and serratus anterior muscle with rib bone free flap $(n=1)$. Total necrosis of the flap was found in four cases (two latissimus dorsi flaps and two fibular flaps). The free flap survival rate was $97.5 \%$. Nineteen patients received radiotherapy before surgery, and none of them experienced flap failure. The mean operation time was $334 \pm 83.1 \mathrm{~min}$, and the mean ischemic time was $48.9 \pm 12.7 \mathrm{~min}$.
\end{abstract}

Conclusions: The success rate was reliable and comparable with previous studies. The success rate was not affected by radiation therapy. Free flaps can be safely used even after radiation treatment.

\section{Background}

Microsurgical reconstruction of the oral and maxillofacial area is a challenging procedure that involves pedicled flaps [1-8]. Reconstructive surgeons should be thoroughly familiar with the anatomy of the donor site and be able to dissect neck vessels and restore damaged structures with available flaps to produce favorable functional and esthetic outcomes.

With improvements in microsurgical techniques and instruments, free tissue transfer has become the most

\footnotetext{
* Correspondence: ahnkm@nate.com

Department of Oral and Maxillofacial Surgery, College of Medicine, University of Ulsan, Asan Medical Center, 88 Olympic-ro, 43-gil, Songpa-gu, Seoul 05505, Korea
}

reliable method for treating head and neck defects. The free flap technique represents a revolution in reconstructive surgery, as it enables the harvesting of a large amount of revascularized tissue, which can be tailored to the defect and allow for more complex reconstructive procedures, while simultaneously permitting more exclude latissimus dorsi (LD) flaps, radial forearm (RF) flaps, scapula flaps, anterolateral thigh flaps, jejunum aps, and rectus abdominis muscle flaps [12-15].

Free flaps have been widely used in Korea after oral cancer and reconstructive surgery; however, there are 
Table 1 Patient characteristics

\begin{tabular}{lllllll}
\hline & RFFF & FFF & LD & SA & Total & \\
\hline Gender, $n(\%)$ & & & & & & \\
Male & $43(66.2)$ & $17(50)$ & $15(71.4)$ & $0(0)$ & 75 & 46 \\
Female & $22(33.8)$ & $17(50)$ & $6(28.6)$ & $1(100)$ & $464^{\mathrm{a}}$ \\
Age, mean (SD) (years) & $60.3(13.4)$ & $58.4(12.2)$ & $59.2(12.1)$ & $13.00(0)$ & $59.2(13.4)$ & $0.25^{\mathrm{b}}$ \\
\hline
\end{tabular}

SD standard deviation, RFFF radial forearm free flap, FFF fibula free flap, LD latissimus dorsi, $S A$ serratus anterior

${ }^{\mathrm{a}}$ Linear-by-linear association

${ }^{\mathrm{b}}$ Kruskal-Wallis test

few reports about flap survival and clinical results of free flap reconstruction [6]. This retrospective study investigated the survival rate, complications, and outcomes of 121 consecutive microsurgical reconstruction cases in a single institution by one experienced surgeon.

\section{Methods}

This study included patients who underwent microsurgical reconstruction with free flaps, from January 2006 through September 2019, performed by a single experienced surgeon at the oral and maxillofacial surgery department of a tertiary medical center. A total of 121 cases were retrospectively reviewed. The flap survival rate, flap type, complications, and treatment results were captured and analyzed. The study protocol was reviewed and approved by the institutional review board of the Asan Medical Center (IRB approval No. 2019-0197).

Microvascular anastomoses were mainly performed using the superior thyroid artery, facial artery, and external carotid artery. Simple interrupted suturing was performed using 9-0 or 10-0 nylon (Ethicon, J\&J Medical Devices, England) sutures. Intraoperatively, a heparin- saline was applied to donor-site and recipient-site blood vessels to prevent vascular coagulation. Doppler monitor was used to confirm the state of the free flap until 7 days after the operation.

The characteristics of patients including primary disease, types of flaps, operation time, ischemic time, and post- and pre-operation radiotherapy were reviewed. The survival of free flap was determined by clinical evaluation in cases of soft tissue flaps and bone scintigraphy in bone flaps. The complications associated with free flap reconstruction were examined retrospectively.

All statistical analyses were performed using SPSS Statistics for Windows, version 21 (IBM Corp., Armonk, NY, USA). Results were presented as either means \pm standard deviations or frequencies with percentages. A $p$ value $<0.05$ was considered statistically significant.

\section{Results}

Table 1 reports the characteristics of the included patients and Figs. 1, 2, 3, and 4 shows the representative case of reconstructed flaps. There were no significant differences in sex ratio or mean age between the groups
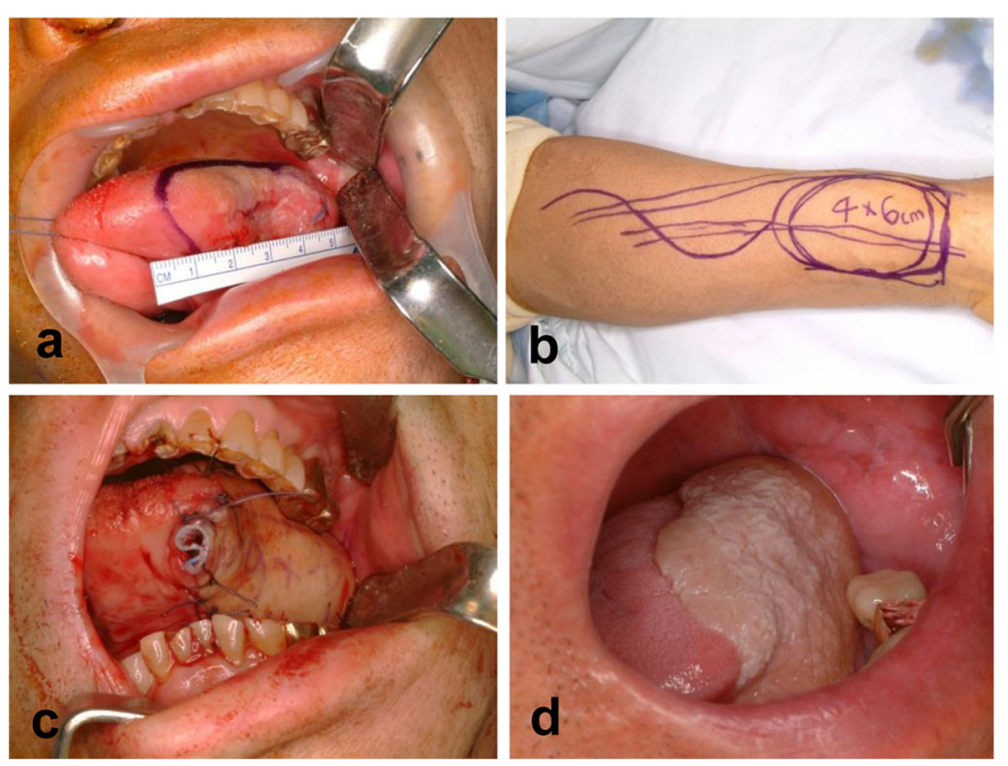

Fig. 1 Surgical approach and clinical results after radial forearm free flap (a left tongue cancer, $\mathbf{b}$ radial forearm free flap design, $\mathbf{c}$ radial forearm free flap reconstruction of the lateral tongue, $\mathbf{d}$ tongue reconstruction 3 years after operation) 

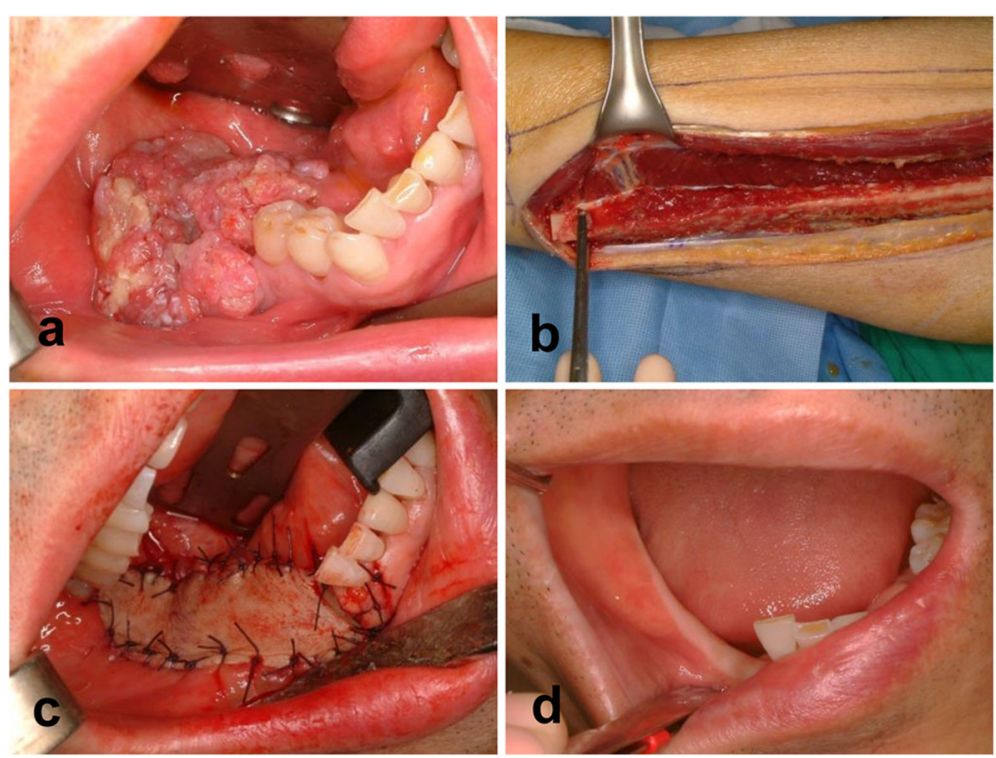

Fig. 2 Surgical approach and clinical results after fibular free flap (a right mandible gingival cancer, b fibular free flap elevation, $\mathbf{c}$ intraoral position of skin paddle, $\mathbf{d}$ intraoral photograph 3 years after operation)

of each flap ( $p=0.64$ and $p=0.25$, respectively). Of the 121 patients, 12 had postoperative complications regarding free flap reconstruction (Table 2). The flap types and the postoperative outcomes are shown in Table 3. Total necrosis of the flap was found in 4 cases (two latissimus dorsi (LD) flap and two fibular flaps) and the failed flaps were debrided. Two LD flaps were reconstructed with the opposite side LD flap. Two failed fibular flaps were debrided and defect sites were healed with secondary intention. The overall survival rate of the free flaps was $97.5 \%$.

The main indication for microsurgical reconstruction was the defect after cancer ablation surgery. The indications for flap reconstruction were listed in Table 4. The mean operation time was varied from $270.6 \pm 50.3$ to $400.1 \mathrm{~min}$ in each flap (Table 5). The mean ischemic time which refers to the time taken during microvascular anastomosis was less than $62.5 \pm 5$ minutes.

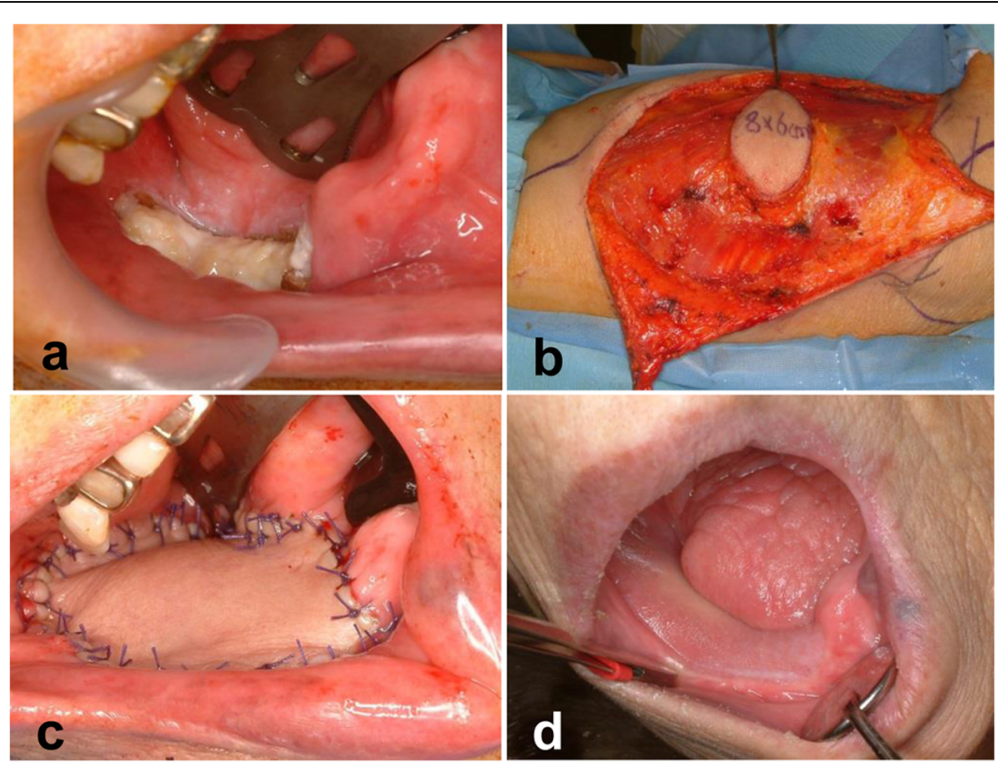

Fig. 3 Surgical approach and clinical results after latissimus dorsi flap (a right gingival cancer with bone invasion, b latissimus dorsi flap elevation, c intraoral position of skin paddle, $\mathbf{d}$ intraoral photograph 3 years after operation) 


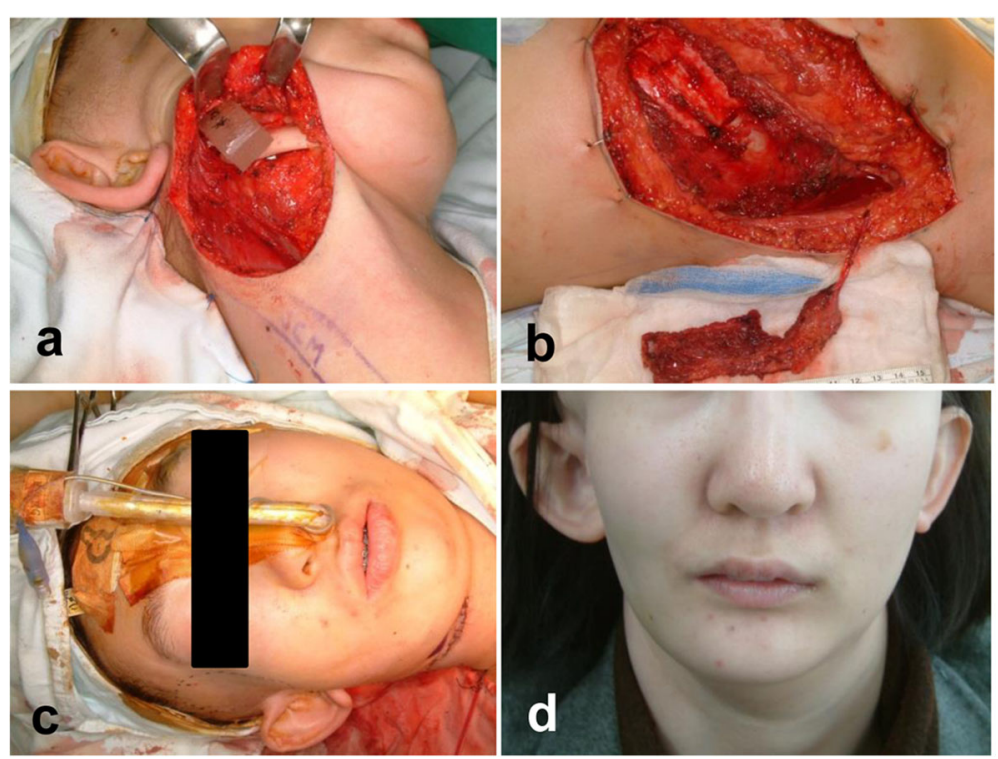

Fig. 4 Surgical approach and clinical results after serratus anterior with rib bone free flap (a exposed right mandible, b elevated flap with rib bone, $\mathbf{c}$ intraoperative photograph for mandible reconstruction, $\mathbf{d}$ facial photograph 5 years after operation)

\section{Discussion}

The success rate of microvascular free flap reconstruction has risen from 70 to $90-99 \%$ over the past 30 years, making it the most reliable surgery in the field of reconstructive surgery [16-19]. In our retrospective study, the overall flap success rate was $97.5 \%$ among 121 consecutive procedures (Table 3). In our department, all of these procedures were performed by one oral and maxillofacial surgeon for 14 years. Therefore, our surgical outcomes have benefited from continuity, as we avoided the impact of differences in skill levels among multiple surgeons or centers.

Few studies investigating operating times for microvascular reconstruction have been published. It has been reported that as the operation time increases, the level of risk increases, particularly in terms of the incidence of rhabdomyolysis, fluid and electrolyte disturbances, deep vein thrombosis, and hypothermia [20,21]. According to

Table 2 Prognostic factors and outcomes

\begin{tabular}{lllllll}
\hline Factor & RFFF & FFF & $\begin{array}{l}\text { SA } \\
\text { flaps }\end{array}$ & $\begin{array}{l}\text { Flap } \\
\text { loss }\end{array}$ \\
\hline $\begin{array}{l}\text { Complications } \\
\quad \text { Arterial thrombosis }\end{array}$ & 0 & 0 & 2 & 0 & 2 & 2 \\
$\begin{array}{l}\text { Venous thrombosis } \\
\text { Fistula }\end{array}$ & 0 & 2 & 0 & 0 & 2 & 2 \\
$\quad 1$ & 2 & 0 & 0 & 3 & 0 \\
$\begin{array}{l}\text { Postoperative bleeding } \\
\text { Seroma }\end{array}$ & 1 & 0 & 2 & 0 & 3 & 0 \\
$\quad 1$ & 1 & 0 & 0 & 2 & 0 \\
$\begin{array}{l}\text { Total } \\
\text { Previous radiation }\end{array}$ & 3 & 5 & 4 & 0 & 12 & 4 \\
therapy & 7 & 8 & 4 & 0 & 19 & 0 \\
\hline
\end{tabular}

various reports [22-25], operation times vary from 376 to $817 \mathrm{~min}$ for maxillofacial microvascular reconstruction. Crawley et al. [26] reported a mean ischemic time of $115.4 \pm 35.7 \mathrm{~min}$ among 849 cases and a mean operation time of $732 \pm 144 \mathrm{~min}$ among 650 cases. They also found that prolonged ischemic times were associated with a higher flap failure rate. In our study, the mean operation time was $334 \pm 83.1 \mathrm{~min}$, and the mean ischemic time was $48.9 \pm 12.7 \mathrm{~min}$, meaning that our procedures were relatively short overall (Table 4).

Our team used 1-team approach for mass excision and microsurgical reconstruction. Theoretically, 2team approach can reduce operative time and operator fatigue. However, the operation time may be increased due to team change during operation. Torabi et al. [27] compared data from 1- and 2-team performing head and neck reconstructive surgery in 2968 patients and reported longer operative time and more complication rates in 2-team approach. Reduction of operation time during microvascular reconstruction can minimize the surgeon's strain and

Table 3 Type of flaps and postoperative outcomes

\begin{tabular}{llll}
\hline Type of flap & Cases $(n)$ & Failures $(n)$ & Success rate (\%) \\
\hline RFFF & 65 & 0 & 100 \\
FFF & 34 & 2 & 94.12 \\
LD & 21 & 2 & 90.48 \\
SA & 1 & 0 & 100 \\
Total & 121 & 4 & 97.5 \\
\hline
\end{tabular}

RFFF radial forearm free flap, FFF fibula free flap, $L D$ latissimus dorsi, $S A$ serratus anterior 
Table 4 Indications for microsurgical reconstruction

\begin{tabular}{|c|c|c|c|c|c|c|}
\hline & $\begin{array}{l}\text { RFFF } \\
(n)\end{array}$ & $\begin{array}{l}\text { FFF } \\
(n)\end{array}$ & $\begin{array}{l}\mathrm{LD} \\
(n) \\
\end{array}$ & $\begin{array}{l}\text { SA } \\
(n)\end{array}$ & Total & $\%$ \\
\hline Squamous cell carcinoma & 57 & 18 & 14 & & 89 & 73.6 \\
\hline Osteoradionecrosis & 2 & 4 & 1 & & 7 & 5.8 \\
\hline BRONJ & & 5 & & & 5 & 4.1 \\
\hline Adenoid cystic carcinoma & 2 & 1 & & & 3 & 2.5 \\
\hline Osteosarcoma & & 2 & 1 & & 3 & 2.5 \\
\hline Ameloblastic carcinoma & 1 & & 1 & & 2 & 1.7 \\
\hline HCC metastasis & & 1 & 1 & & 2 & 1.7 \\
\hline $\begin{array}{l}\text { Mucoepidermoid } \\
\text { carcinoma }\end{array}$ & 1 & 1 & & & 2 & 1.7 \\
\hline Spindle cell sarcoma & 1 & & 1 & & 2 & 1.7 \\
\hline Ameloblastoma & & 1 & & & 1 & 0.8 \\
\hline Flap necrosis & & & 1 & & 1 & 0.8 \\
\hline Parotid tumor & & 1 & & & 1 & 0.8 \\
\hline Postoperation bleeding & & & 1 & & 1 & 0.8 \\
\hline Rhabdomyosarcoma & & & & 1 & 1 & 0.8 \\
\hline Verrucous carcinoma & 1 & & & & 1 & 0.8 \\
\hline Total & 65 & 34 & 21 & 1 & 121 & 100 \\
\hline
\end{tabular}

RFFF radial forearm free flap, FFF fibula free flap, $L D$ latissimus dorsi, $S A$ serratus anterior, BRONJ bisphosphonate-related osteonecrosis of the jaw, $H C C$ hepatocellular carcinoma

fatigue as well as reduce the risk of postoperative complications such as wound infections, hematomas, seromas, and dehiscence. The surgeon's factor such as excellent microsurgical technique and experiences are important determinants for successful reconstruction [28].

Preoperative radiotherapy has been reported to be associated with a higher risk of free flap failure and complications [29]. In fact, radiotherapy causes microscopic and macroscopic vascular changes [30-32]. In our study, however, the 19 patients who had previously undergone radiation therapy had a $100 \%$ survival rate. Gordin and Ducic [33] reported that microvascular surgery could be successful among patients who have received multiple courses of preoperative radiation. It is clear that patients undergoing radiation therapy at the surgical site have an increased risk of postoperative complications. However, this disadvantage can be overcome by careful selection of blood vessels, with considerations such as adequate vessel diameter and vessels contralateral to the side of the body that was irradiated.

Anatomical limitations, such as vessel depletion, can increase operation times or make it difficult to find reliable recipient blood vessels. However, Nahabedian et al. [34] reported no correlation between the rates of flap necrosis and the choice of recipient vessels, the use of an interposition vein graft, the method of venous or arterial anastomosis, or the timing of reconstruction. In our retrospective study, four patients experienced total flap loss, but we did not observe any primary vessel depletion intraoperatively.

Some authors $[35,36]$ have reported that age alone should not be considered an independent risk factor or contraindication when considering free flap transfer. Ferrari et al. [35] reported a $98.2 \%$ free flap success rate among patients over 75 years of age and a $96.2 \%$ success rate among patients under 75 years of age. Tarsitano et al. [36] described the free flap success rate to be similar among patients over 75 years of age compared with the general population. In our study, we observed a mean age of 59.2 years (range, 18 to 84 years), with flap loss occurring in one of seven patients over 75 years.

In head and neck microvascular reconstruction, flap failure is usually caused by vascular thrombosis [37, 38] . Of the 121 cases in this study, flap failure occurred in 2 cases in LD flap and 2 cases in fibula free flap. In case of LD flap failure, vessel kinking occurred due to bulky flap size, resulting in arterial flow deficiency. In one of the fibula flap fail cases, flap necrosis happened after RT. It might be related with vessels damage due to high dose of RT. The other case failed due to venous thrombosis. Common causes of venous thrombosis are vasospasm caused by hypothermia, hypotension, and mechanical stress during anastomosis [39]. On the other hand, arterial thrombosis is caused by vessel kinking, bleeding, and extrinsic compression [40]. One patient experienced postoperative bleeding with RFFF. During bleeding control and debridement, the surgical defect became larger than the first surgery and neck vessels were exposed. In order to protect the carotid artery with a thick muscle layer, the existing flap was removed and LD flap was performed.

All patients were monitored immediately after reconstruction surgery. Experienced surgeon checked flap

Table $\mathbf{5}$ Ischemic time and surgical procedure time for free flap reconstruction

\begin{tabular}{|c|c|c|c|c|c|c|c|c|c|c|}
\hline & \multicolumn{2}{|l|}{ RFFF } & \multicolumn{2}{|l|}{ FFF } & \multicolumn{2}{|l|}{$\underline{L D}$} & \multicolumn{2}{|l|}{ SA } & \multicolumn{2}{|l|}{ Total } \\
\hline & Mean & $\pm \mathrm{SD}$ & Mean & $\pm \mathrm{SD}$ & Mean & $\pm S D$ & Mean & $\pm S D$ & Mean & $\pm S D$ \\
\hline Ischemic time (min) & 36.3 & 7.5 & 47.5 & 9.6 & 62.5 & 5 & 52.5 & - & 48.9 & 12.7 \\
\hline Operation time (min) & 270.6 & 50.3 & 345.3 & 70.4 & 381.8 & 91.3 & 400.1 & - & 334.0 & 83.1 \\
\hline
\end{tabular}

$S D$ standard deviation, RFFF radial forearm free flap, FFF fibula free flap, $L D$ latissimus dorsi, $S A$ serratus anterior 
color and temperature every $8 \mathrm{~h}$ for the first $72 \mathrm{~h}$. The risk of thrombosis is the highest at $80 \%$ by postoperative day 2 and decreases by $10 \%$ after 3 postoperative days [41]. Arterial crises manifest as pale flaps, capillary refill longer than $1 \mathrm{~s}$, a lack of bleeding after a pinprick, and low flap temperature.

\section{Conclusions}

Microsurgical reconstruction is the most versatile method for restoring large defects in the head and neck, and it has major implications in terms of patient quality of life. The success rate in our series was high at $97.5 \%$. Microvascular free tissue transfer can also be successfully performed for patients who have undergone radiation therapy. Complications should be prevented by using a meticulous surgical technique and performing careful postoperative monitoring.

\section{Acknowledgements}

No

\section{Authors' contributions}

Seong Ryoung Kim and Dong-Hun Lee participated in writing the introduction, discussion, and data collection. Kang-Min Ahn conceived of the study, participated in its design and coordination, and helped to draft the manuscript. All authors read and approved the final manuscript.

\section{Authors' information}

Seong Ryoung Kim and Dong-Hun Lee are senior resident in the Department of Oral and Maxillofacial Surgery, College of Medicine, University of Ulsan, Asan Medical center, Seoul, Korea.

\section{Funding}

No funding

\section{Availability of data and materials}

All the data were retrieved from electronic medical chart of Asan Medical Center.

\section{Ethics approval and consent to participate}

The study protocol was reviewed and approved by the institutional review board of the Asan Medical Center (IRB approval No. 2019-0197).

\section{Consent for publication}

Consent forms of all patients were obtained before operation.

\section{Competing interests}

No competing interests regarding this study

Received: 9 July 2020 Accepted: 12 August 2020

Published online: 26 August 2020

\section{References}

1. Anand R, Ethunandan M, Pratt C (2006) Re: Kissun D, Shaw R J, Vaughan E D. survival of a free flap after arterial disconnection at six days. Br J Oral Maxillofac Surg 2004;42:163-5. Br J Oral Maxillofac Surg 44:338-339

2. Blanchaert RH Jr (2012) Survival after free flap reconstruction in patients with advanced oral squamous cell carcinoma. J Oral Maxillofac Surg 70:460

3. Castling B, Avery C (2003) Re: Godden DRP, Thomas SJ. Survival of a free flap after vascular disconnection at 9 days. Br J Oral Maxillofac Surg 2002; 40 : 446-447. Br J Oral Maxillofac Surg 41:281-281

4. Ch'ng S, Choi V, Elliott M, Clark JR (2014) Relationship between postoperative complications and survival after free flap reconstruction for oral cavity squamous cell carcinoma. Head Neck 36:55-59
5. de Vicente JC, Rodriguez-Santamarta T, Rosado P, Pena I, de Villalain L (2012) Survival after free flap reconstruction in patients with advanced oral squamous cell carcinoma. J Oral Maxillofac Surg 70:453-459

6. Li BH, Jung HJ, Choi SW, Kim SM, Kim MJ, Lee JH (2012) Latissimus dorsi (LD) free flap and reconstruction plate used for extensive maxillo-mandibular reconstruction after tumor ablation. J Craniomaxillofac Surg 40:e293-e300

7. Marchetti C, Pizzigallo A, Cipriani R, Campobassi A, Badiali G (2008) Does microvascular free flap reconstruction in oral squamous cell carcinoma improve patient survival? Otolaryngol Head Neck Surg 139:775-780

8. Lin TR, Yang Cl, Wu CY, Liao YM (2013) Project to improve the free flap survival rate in oral cancer microreconstruction free flap surgery. Hu Li Za Zhi 60:68-75

9. Zhang X, Li MJ, Fang QG, Sun CF (2014) A comparison between the pectoralis major myocutaneous flap and the free anterolateral thigh perforator flap for reconstruction in head and neck cancer patients: assessment of the quality of life. J Craniofac Surg 25:868-871

10. Futran ND, Mendez E (2006) Developments in reconstruction of midface and maxilla. Lancet Oncol 7:249-258

11. de Bree R, Rinaldo A, Genden EM, Suarez C, Rodrigo JP, Fagan JJ et al (2008) Modern reconstruction techniques for oral and pharyngeal defects after tumor resection. Eur Arch Otorhinolaryngol 265:1-9

12. Neligan PC (2013) Head and neck reconstruction. Plast Reconstr Surg 131: $260 \mathrm{e}-269 \mathrm{e}$

13. Markey J, Knott PD, Fritz MA, Seth R (2015) Recent advances in head and neck free tissue transfer. Curr Opin Otolaryngol Head Neck Surg 23:297-301

14. Borah GL, Hidalgo DA, Wey PD (1995) Reconstruction of extensive scalp defects with rectus free flaps. Ann Plast Surg 34:281-285 discussion 285-287

15. Sweeny L, Eby B, Magnuson JS, Carroll WR, Rosenthal EL (2012) Reconstruction of scalp defects with the radial forearm free flap. Head Neck Oncol 4:21

16. Khouri RK, Shaw WW (1989) Reconstruction of the lower extremity with microvascular free flaps: a 10-year experience with 304 consecutive cases. J Trauma 29:1086-1094

17. Gusenoff JA, Vega SJ, Jiang S, Behnam AB, Sbitany H, Herrera HR et al (2006) Free tissue transfer: comparison of outcomes between university hospitals and community hospitals. Plast Reconstr Surg 118:671-675

18. Almadori G, Rigante M, Bussu F, Parrilla C, Gallus R, Barone Adesi L et al (2015) Impact of microvascular free flap reconstruction in oral cavity cancer: our experience in 130 cases. Acta Otorhinolaryngol Ital 35:386-393

19. Tarsitano A, Ciocca L, Cipriani R, Scotti R, Marchetti C (2015) Mandibular reconstruction using fibula free flap harvested using a customised cutting guide: how we do it. Acta Otorhinolaryngol Ital 35:198-201

20. Fogarty BJ, Khan K, Ashall G, Leonard AG (1999) Complications of long operations: a prospective study of morbidity associated with prolonged operative time (> 6 h). Br J Plast Surg 52:33-36

21. Procter LD, Davenport DL, Bernard AC, Zwischenberger JB (2010) General surgical operative duration is associated with increased risk-adjusted infectious complication rates and length of hospital stay. J Am Coll Surg 210(60-65):e61-e62

22. Brady JS, Desai SV, Crippen MM, Eloy JA, Gubenko Y, Baredes S et al (2018) Association of anesthesia duration with complications after microvascular reconstruction of the head and neck. JAMA Facial Plast Surg 20:188-195

23. Lin JA, Loh CYY, Tsai CH, Chang KP, Wu JC, Kao HK (2019) Free flap outcomes of microvascular reconstruction after repeated segmental mandibulectomy in head and neck cancer patients. Sci Rep 9:7951

24. Mucke T, Ritschl LM, Roth M, Gull FD, Rau A, Grill S et al (2016) Predictors of free flap loss in the head and neck region: a four-year retrospective study with 451 microvascular transplants at a single Centre. J Craniomaxillofac Surg 44:1292-1298

25. Wahmann M, Wahmann M, Henn D, Xiong L, Hirche C, Harhaus L et al (2020) Geriatric patients with free flap reconstruction: a comparative clinical analysis of 256 cases. J Reconstr Microsurg 36:127-135

26. Crawley MB, Sweeny L, Ravipati $P$, Heffelfinger $R$, Krein $H$, Luginbuhl A et al (2019) Factors associated with free flap failures in head and neck reconstruction. Otolaryngol Head Neck Surg 161:598-604

27. Torabi SJ, Chouairi F, Dinis J, Alperovich M (2020) Head and neck reconstructive surgery: characterization of the one-team and two-team approaches. J Oral Maxillofac Surg 78:295-304

28. Hardy KL, Davis KE, Constantine RS, Chen M, Hein R, Jewell JL et al (2014) The impact of operative time on complications after plastic surgery: a multivariate regression analysis of 1753 cases. Aesthet Surg J 34:614-622 
29. Herle P, Shukla L, Morrison WA, Shayan R (2015) Preoperative radiation and free flap outcomes for head and neck reconstruction: a systematic review and meta-analysis. ANZ J Surg 85:121-127

30. Benatar MJ, Dassonville O, Chamorey E, Poissonnet G, Ettaiche M, Pierre CS et al (2013) Impact of preoperative radiotherapy on head and neck free flap reconstruction: a report on 429 cases. J Plast Reconstr Aesthet Surg 66:478482

31. Cheng SW, Wu LL, Ting AC, Lau H, Lam LK, Wei WI (1999) Irradiationinduced extracranial carotid stenosis in patients with head and neck malignancies. Am J Surg 178:323-328

32. Yoshimoto S, Kawabata K, Mitani H (2010) Factors involved in free flap thrombosis after reconstructive surgery for head and neck cancer. Auris Nasus Larynx 37:212-216

33. Gordin EA, Ducic Y (2014) Microvascular free tissue reconstruction in the patient with multiple courses of radiation. Laryngoscope 124:2252-2256

34. Nahabedian MY, Singh N, Deune EG, Silverman R, Tufaro AP (2004) Recipient vessel analysis for microvascular reconstruction of the head and neck. Ann Plast Surg 52:148-155 discussion 156-147

35. Ferrari S, Copelli C, Bianchi B, Ferri A, Poli T, Ferri T et al (2013) Free flaps in elderly patients: outcomes and complications in head and neck reconstruction after oncological resection. J Craniomaxillofac Surg 41:167171

36. Tarsitano A, Pizzigallo A, Sgarzani R, Oranges CM, Cipriani R, Marchetti C (2012) Head and neck cancer in elderly patients: is microsurgical free-tissue transfer a safe procedure? Acta Otorhinolaryngol Ital 32:371-375

37. Ross DA, Chow JY, Shin J, Restifo R, Joe JK, Sasaki CT et al (2005) Arterial coupling for microvascular free tissue transfer in head and neck reconstruction. Arch Otolaryngol Head Neck Surg 131:891-895

38. Fukuiwa T, Nishimoto K, Hayashi T, Kurono Y (2008) Venous thrombosis after microvascular free-tissue transfer in head and neck cancer reconstruction. Auris Nasus Larynx 35:390-396

39. Ozbek MR, Deune EG, Cooley BC, Khouri RK (1994) Experimental reproduction of free flap errors: a new model of thrombosis. Ann Plast Surg 32:474-477

40. Seo MH, Kim SM, Huan F, Myoung H, Lee JH, Lee SK (2015) Analysis of microvascular free flap failure focusing on the microscopic findings of the anastomosed vessels. J Craniofac Surg 26:2047-2051

41. Yii NW, Evans GR, Miller MJ, Reece GP, Langstein H, Chang D et al (2001) Thrombolytic therapy: what is its role in free flap salvage? Ann Plast Surg 46:601-604

\section{Publisher's Note}

Springer Nature remains neutral with regard to jurisdictional claims in published maps and institutional affiliations.

\section{Submit your manuscript to a SpringerOpen ${ }^{\circ}$ journal and benefit from:}

- Convenient online submission

- Rigorous peer review

- Open access: articles freely available online

- High visibility within the field

- Retaining the copyright to your article

Submit your next manuscript at $\boldsymbol{\nabla}$ springeropen.com 